\title{
National Corporate Pharmacy and Therapeutic Committee at the Ministry of Health, Saudi Arabia
}

\author{
Yousef Ahmed Alomi, (iD The \\ Former General Manager of General \\ Administration of Pharmaceutical \\ Care, The Former Head, National Clini- \\ cal pharmacy and pharmacy practice, \\ The Former Head, Pharmacy R and \\ D Administration, Ministry of Health, \\ Riyadh, SAUDI ARABIA. \\ Saeed Jamaan Alghamdi, General \\ Administration of Pharmaceutical \\ Care, Ministry of Health, Riyadh, \\ SAUDI ARABIA.
}

Radi Abdullah Alattyh, General Administration of Pharmaceutical Care, Ministry of Health, Riyadh, SAUDI ARABIA.

\section{Correspondence:}

Dr. Yousef Ahmed Alomi,

The Past General Manager of General Administration of Pharmaceutical Care, The Past Head, National Clinical Pharmacy and Pharmacy Practice, The Past Head, Pharmacy R and D Administration, Ministry of Health, Riyadh, SAUDI ARABIA.

Phone no: +966504417712

E-mail: yalomi@gmail.com

Received: 05-07-2018;

Accepted: 15-08-2018

Copyright: $\odot$ the author(s),publisher and licensee Pharmacology, Toxicology and Biomedical Reports. This is an open-access article distributed under the terms of the Creative Commons Attribution NonCommercial License, which permits unrestricted non-commercial use, distribution, and reproduction in any medium, provided the original work is properly cited.

This is an open access article distributed under the terms of the Creative Commons Attribution-NonCommercial-ShareAlike 4.0 License

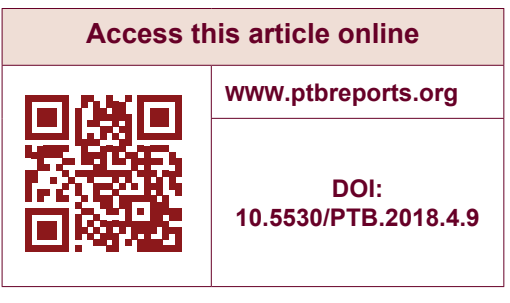

\begin{abstract}
Objective: To review the Ministry of Health Corporate MOH Pharmacy and Therapeutic committee system at the Ministry of Health foundations in the Kingdom of Saudi Arabia. Method: It is a retrospective analysis of Ministry of Health Corporate $\mathrm{MOH}$ Pharmacy and Therapeutic committee system at Ministry of hospitals institutions. Its analysis illustrated within the Pharmacy strategic plan 2012-2020. The analysis process used. The modified pharmacy business model system and Project Management Procedure. Results: Ministry of Heath drug Corporate MOH Pharmacy and Therapeutic committee established with clear vision, mission and goals. The committee had human or economic and other resources described in the review. To assure the continuity of the system; the risk management was used and described. Besides, the monitoring and controlling of the system were demonstrated. The closing stage with convention to operation project shown in the Analysis. Conclusion: The Ministry of Health Corporate MOH Pharmacy and Therapeutic committee system founded though Pharmacy strategies and regulations. The Ministry of Health Corporate MOH Pharmacy and Therapeutic committee has regular development accordingly at all Ministry of Health hospitals and primary healthcare centers in the Kingdom of Saudi Arabia.
\end{abstract}

Key word: Pharmacy and Therapeutic Committee, Ministry of Health, Saudi Arabia.

\section{INTRODUCTION}

The international societies of pharmacy set up the guidelines for the distribution of the drug in the hospitals. They are also responsible for the establishment of the committee responsible for the organization and regulation of the distribution of medications at all stages and procedures; this committee mainly consists of medical staff, which is known as Pharmacy and Therapeutic Committee (PTC). ${ }^{1}$ PTC became mandated across all hospitals of national and international accreditation standards. ${ }^{2,3}$ Several studies conducted about PTC show pattern of practice, membership, meetings and regulations. ${ }^{4-7}$ However, to the best of our knowledge, there are no investigations about the description of PTC with an emphasis at $\mathrm{MOH}$ in the Kingdom of Saudi Arabia (KSA), Gulf and the Middle Eastern countries. Therefore, in this review, we aimed to explore the corporate PTC at the $\mathrm{MOH}$ in Saudi Arabia.

\section{History of the Corporate PTC at MOH}

The PTC at MOH institution was initially started at the King Saud Medical Complex in the late 1980s. In the 1990s, the clinical pharmacy services were started at the hospital with the drug information center. The committee first published the MOH's drug formulary in the mid-1990s. The committee updates the drug formulary during the follow-up assessment of all drug formularyrelated issues. In 2002, the updated drug formulary was more organized with members work inside and outside the $\mathrm{MOH}$ came on the ground. ${ }^{1}$
The committee is continuing to grow with the following new systems added: deletion request system, an adverse drug reaction system, medication error reporting system and drug quality reporting system..$^{2,3}$ In 2012, clinical pharmacists from the $\mathrm{MOH}$ including the author of this study and members from the regional drug information center from King Saud Medical City formed the new members of PTC. These new members designed and organized the cooperate PTC by updating all related follow-up guidelines on medication safety and drug-related problems. ${ }^{1}$

\section{History of the General Administration of Pharmaceutical Care (GAPC)}

GAPC went through four stages of development and modification as the following:

\section{The Initial Stage of the Construction Phase}

During the period 2000 to 2001, the task force team consisted of new the Pharmaceutical Care Department and Hospital Riyadh Central members and headed by Deputy Minister for Affairs Executive. The task force team established the Pharmaceutical Care administration functions and organizational structure. As resulted, Minister of Health on 21 December 2001issued the resolution to formulate the Pharmaceutical Care Administration headed by an expert pharmacist and reported directly to the Deputy Minister for Affairs Executive. 


\section{The Second Stage of the Construction Phase}

During the period (2001-2007), the workforces of the pharmaceutical care administration founded and consisted of the director and five staff pharmacists with an additional supportive personal secretarial section. The Department of Pharmaceutical Care at all departments of Health Affairs across all cities and provinces have been established. The policies and procedures in hospitals and Primary healthcare centers released. The pharmacists' scholarship for the master's and Doctorate in different specialties started. Moreover, the bridging pharmacy technician' scholarship to complete a Bachelor degree in Pharmacy overseas in the United States, Britain and Australia.

\section{The Third Stage of the Developmental Phase}

During the period (2007-2012), the first pharmacy strategic plan was developed for all pharmacies located at all healthcare institution at the Ministry of Health. The basic foundation of hospital pharmacy, objectives and the standards of pharmaceutical care, the implementation system was released. The pharmaceutical care administration participated with the Gulf Cooperation Council (GCC) Committee of pharmaceutical care at the Executive Office of the Council of Ministers of Health in the Gulf area. The pharmaceutical care administration conducted several conferences of pharmacy practice at several regions of KSA, including Jazan, Hail, Najran, Eastern Province and Tabuk. The pharmaceutical care administration participated in the committees of the drug registration at $\mathrm{MOH}$ as well as many scientific committees to lay the foundations for the optimal use of the drug in therapeutic protocols. Also, the pharmaceutical care department participated in the task force committee of the establishment of the Saudi Food and Drug Authority. The pharmaceutical care administration upgraded in the last period to the General Administration of Pharmaceutical Care (GAPC).

\section{The Fourth Stage of the Advanced Developmental Phase 2012 to 2015}

The first author as clinical pharmacist specialized in the critical care services and nutrition support pharmacy, He had a Master degree in the Clinical Pharmacy and board certification specialty in pharmacotherapy and nutrition support, with more than 15 years of experience in the practice of pharmacy and ten years in clinical pharmacy. The Minster of Health assigned him as General Manager of Pharmaceutical Care in 2012. In this period, the General Administration of Pharmaceutical Care (GAPC) developed the update Pharmacy Strategic Plan 2012-2022. ${ }^{8}$ The pharmacy plan approved by the Executive Board of the $\mathrm{MOH}$ headed by Minister of Health. The updated organizational structure of the GAPC done in this period. The standard of pharmacist workforce's requirement per each hospital and Primary healthcare centers released. ${ }^{9,10}$ The pharmacist competencies and patient satisfaction of pharmaceutical services established. ${ }^{11,12}$ GAPC developed clinical pharmacy scholarship and determine disciplinary career pathway in practice. Besides, GAPC implemented more than 30 programs and 45 committees in clinical pharmacy and pharmacy practice, then started a comprehensive program of national medication safety. ${ }^{13-15}$ Moreover, the GAPC founded scientific research policy and procedures and encouraged all pharmacists to participate in the biomedical journals and published scientific research.

\section{Method of Development of the Project}

The descriptive history of corporate PTC in the period from 2002 to 2016 at the $\mathrm{MOH}$ in Saudi Arabia. The task force committee consisted of expert people from the pharmacies of the $\mathrm{MOH}$ hospitals to set up corporate PTC at $\mathrm{MOH}$ system for all healthcare institutions. The author of this article headed the task force. The draft was sent to several reviewers of the RAPC. The draft was corrected and updated accordingly. The analysis included membership, objectives of the committee, the activities of the committee and method of drug evaluation of addition or deletion medications. Moreover, by the project written by using the international business model, pharmacy guidelines, project management institution guidelines for a new project. ${ }^{16-19}$

\section{Initiative Phase}

\section{Assessment Needs}

The central or corporate PTC at $\mathrm{MOH}$ is demanding for a $\mathrm{MOH}$ drug formulary management, setting up of therapeutic guidelines for all $\mathrm{MOH}$ institutions, follow-up of ADR of medications, follow-up of medications safety reports and addition and deletion with the decision making of drug formulary.

\section{Market Analysis}

Each governmental or private healthcare institutions should establish a local PTC as the legal body in the accreditation process. However, there is no central committee which coordinates among all the committees. There is one committee which works like MOH's corporate PTC at National Guard Healthcare Institutions in a small number of hospitals.

\section{SWOT Analysis}

We performed a SWOT analysis in this review. The strengths were central regulation which coordinated the functions of PTCs across all $\mathrm{MOH}$ hospitals, activated and followed-up peripheral PTCs, implemented the therapeutic guidelines and arranged one $\mathrm{MOH}$ drug formulary. The weak points were a delay of working and function of PTC and central working related problems. The opportunities were the implementation of national and international standards and invite expert pharmacist from outside $\mathrm{MOH}$ institution. The threat points were privatization of implementation at $\mathrm{MOH}$ institutions.

\section{Planning phase}

\section{The Scope of the Project}

The project included the corporate PTC at $\mathrm{MOH}$ over the past several years until 2015. The stages of development of corporate PTC, the method of communication between the corporate PTCs and peripheral PTCs and pharmacy directors at $\mathrm{MOH}$ hospitals in the KSA.

\section{Vision, Missions and Goals}

The vision of this project is defined as the best implementation of fiction corporate PTC at $\mathrm{MOH}$ institution. The mission of this project is stated to provide and implement the full functions of corporate PTC though the $\mathrm{MOH}$ institution base on national and international standards. The project's goals were to implement the function corporate PTC cross $\mathrm{MOH}$ institution, to activate and follow-up the peripheral PTC at all healthcare institutions and to provide full pharmaceutical care to patients at all healthcare settings.

\section{Project description}

Request for addition or cancellation of a drug in the MOH's Drug Directory as explored in the algorithm ${ }^{1}$ are as follows:

A. Request by a physician or pharmacist for inclusion of a drug.

- The request form prepared by the healthcare provider must be filled in.

- The filled-up application form must be referred to the Director of Pharmacy as well as to the Coordinator (drug information pharmacist) of the PTC at the hospital.

- The Coordinator of the PTC (drug information pharmacist) must examine the request form and evaluate the drug based on the evi- 
dence available and prepare a comprehensive report about the drug (according to the guidelines).

- The PTC at the hospital studies the drug as well.

- In the case of postponement of the decision about the drug, or if the drug is not approved, then the physician must be contacted.

- In case the drug is approved, the application must be sent to the Directorate General of Health Affairs, the Pharmaceutical Care Administration in the Directorate, as well as to the PTC for further study.

- In the case of postponement or nonapproval, the PTC at the hospital must submit a request or notify from the healthcare providers.

- In case the drug is approved, the request form must be sent to the GAPC at the MOH to be submitted to the corporate PTC.

- In case of the postponement or nonapproval of the drug by the GAPC committee, then the GAPC must address this issue with the General Directorate of Health Affairs.

- In the event of approval of the drug, GAPC must address the Medical Supply Department to include the drug in the directory.

- In the event of approval of the drug, a copy of the letter must be forwarded to the General Directorate of Medical Licenses.

- In the event of approval of the drug, a copy of the letter must be forwarded to the database in GAPC.

\section{Planning Cost Management}

The corporate PTC and the related peripheral committee should consider the annual budget for membership attendance, education and training courses, the subscription of scientific references and regular visiting for all 20 regions.

\section{Execution Phase}

\section{Management Team}

Formation of the Corporate PTC with the following Members

- Head of Pharmaceutical Care Administration as the Chairman and the following members.

- Head of the Department of Clinical Pharmacy or chairman of the Clinical Pharmacy Committee or the Vice-Chairman.

- Supervisor of the Drug Information Center at the $\mathrm{MOH}$ or head of the Central Drug

- An information center's committee.An internal consultant physician or a practitioner in a district hospital.

- A consultant pediatrician in a hospital in the region.

- A representative from a primary care consultancy or a family doctor from the general administration of primary care centers.

- A consultant surgeon from the general administration of hospitals.

- A representative from the general administration of nursing.

- A representative of general administration of quality management and patient safety.

- A representative of the corporate medication safety.

- A representative of the regional general administration of medical supply.

- A pharmacist specialized in informatics in a hospital.

- A clinical pharmacist practicing in a district hospital.

- A clinical pharmacist practicing in a primary healthcare center.

- A clinical pharmacist specialized in the pharmacoeconomics.
Formation of the Regional PTC at the Directorate of Health Affairs as follows

- Director of Pharmaceutical Care at the Directorate as chairman and the following members.

- Head of the Department of Clinical Pharmacy or Chairman of the Clinical Pharmacy Committee or the Vice President.

- Supervisor of the Drug Information Center in the Directorate or head of the regional drug information Centers Committee.

- An internal consultant physician or a practitioner in a district hospital.

- A consultant pediatrician in a hospital in the region.

- A doctor who is a primary care consultant or a family doctor practicing in a hospital in the region.

- A consultant surgeon in a district hospital.

- A representative from the nursing department.

- A representative of quality management and patient safety.

- A representative of the regional medication safety.

- A representative of the regional Department of Medical Supply.

- A pharmacist specialized in informatics in a hospital.

- A clinical pharmacist practicing in a district hospital.

- A clinical pharmacist practicing in a primary healthcare center.

- A clinical pharmacist specialized in the pharmacoeconomics.

\section{Formation of the hospital PTC as follows}

- Medical Director or Consultant Internal Medicine as chairman and the following members.

- Director of Pharmacy Care at the hospital, or the Vice-Director.

- Supervisor of the Drug Information Center.

- Head of Clinical Pharmacy Department.

- An internal medicine consultant or specialist in the hospital.

- A consultant pediatrician or hospital specialist.

- A consultant surgeon or hospital specialist.

- A representative from the nursing department at the hospital.

- A representative of the quality management and safety of patients at the hospital.

- Head of medication safety section.

- Pharmacy Informatics.

- The representative of the Department of Medical Supply.

- Head, Clinical Pharmacy Department.

- Clinical pharmacist practicing at the hospital.

- Clinical pharmacist specialized in the pharmacoeconomics.

Formation of the Primary Care Healthcare Centers PTC as follows

- Consultant doctor, family doctor, or a specialist from primary care centers as chairman and following members.

- Director of Primary Care Pharmacy or Vice-President.

- Supervisor of the Pharmacy Informatics Center in the sector.

- Head of Clinical Pharmacy Department at primary care centers.

- Consultant pediatrician at primary care centers.

- A representative from the nursing department at the primary care centers. 
- A representative of quality management and safety of patients in the sector.

- Head of the Department of Medication Safety at primary care centers.

- Pharmacist practicing at a health center.

- Clinical pharmacist practicing in the primary care centers.

- Clinical pharmacist specialized in the pharmacoeconomics at primary care centers.

\section{Education and Training}

PTC conducted annual education and training programs for pharmacy professionals at the $\mathrm{MOH}$. In addition, the drug information committee conducted several educational and training programs on the addition and deletion of medications in the drug formulary at the $\mathrm{MOH}$. Advanced courses may be conducted in the future with respect to drug evaluation.

\section{Risk Management}

There are six types of risks: budget, scope, personal, schedule, technical and quality risks. Most of the risks experienced might be due to budget, personal, or schedule risks and quality risks. A budget risk is related to unavailability of enough funds for meetings. A project might experience personal risk which might be related to the shortage of human resources in their pharmacy or because there is not enough qualified or specialized pharmacist available to be the member of the committee. In addition, the project might experience personal risk because of the lack of education and training by the corporate PTC members. A project might experience scope risk when there is not enough trained members in the corporate PTC to understand the scope, functions and goals of the project. A project might be exposed to schedule risk when there is a delay in the timing of meeting to be held or when there is no meeting being conducted at all. A project might be exposed to quality risks when nonqualified pharmacist is available and training in the quality pharmacy tools for corporate PTC documentation or measurement or monitoring tools. A project might be exposed to other technical risks such as no availability of an electronic system for the documentation, reporting and scoring with friendly used system.

\section{Monitoring and Controlling Phase Project Quality Management}

The corporate PTC need several Key Performance Indicators (KPIs) to follow the instructions and measure the outcomes. For instance, number of meetings annually held, completed minutes of the meeting, adherence of policies and procedures as per the international PTC guidelines and regulations, number of the memo for healthcare providers about prescribing regulation, number of addition and deletion of medications and updating of $\mathrm{MOH}$ drug formulary. ${ }^{8,14}$

\section{The Closing of the Project}

The corporate PTC at $\mathrm{MOH}$ institutions control drug distribution and prevent misuse of medications in the KSA. The corporate PTC must provide an annual report of assessment. Education and training must be conducted for the healthcare providers regularly with regard to new medications and drug regulations. Further expanded of the project additional the cost avoidance of control and prevention of drugs misuse in the future and annual celebration with project members.

Kindly provide the Materials and Methods

\section{ACKNOWLEDGMENT}

I want to thank all inventory management and medical supply pharmacists in all regions for their cooperation.

\section{CONFLICT OF INTEREST}

The authors declare no conflict of interest.

\section{ABBREVIATIONS}

KSA: Kingdom of Saudi Arabia; MOH: Ministry of Health; PTC: Pharmacy and Therapeutic Committee; RPCA: Regional Pharmaceutical Care Administration; GPCA: General Pharmaceutical Care Administration.

\section{ORCID ID}

Yousef Ahmed Alomi (D) https://orcid.org/0000-003-1381-628X.

\section{REFERENCES}

1. Abazia DT, Anderson P, Azzopardi LM, Baker KR, Besier JL, Bootman JL, et al. ASHP statement on the pharmacy and therapeutics committee and the formulary system. Am J Heal Pharm. 2008;65(24):2384-6.

2. Medication Management (MM). In: National Hospital Standards. $2^{\text {nd }}$ Editio Saudi Central Board for Accreditation of Healthcare Institutions. 2015;194-211.

3. The Joint Commission. 2016 Comprehensive Accreditation Manuals. Joint Commission Resources. 2016.

4. Rotem R, Reuveni H, Goldberg A. Activities, Functions and Structure of Pharmacy and Therapeutics Committees in Israeli Hospitals. Value Heal. 2001;4(2):170.

5. Alkelya M, Kreling D. The Impact of the Pharmacy and The rapeutics Committee on the Patients' Access To Prescription Drugs in the Saudi Ministry of Health: Exploratory and Comparison Study. Value Heal. 2006;9(3):A149.

6. Puigventós F, Santos-Ramos B, Ortega A, Durán-García E. Structure and procedures of the pharmacy and therapeutic committees in Spanish hospitals. Pharm World Sci. 2010;32(6):767-75.

7. Mannebach MA, Ascione FJ, Gaither CA, Bagozzi RP, Cohen IA, Ryan ML. Activities, functions and structure of pharmacy and therapeutics committees in large teaching hospitals. Am J Heal Pharm. 1999;56(7):622-8.

8. Alomi YA, Alghamdi SJ, Alattyh RA. Strategic Plan of General Administration of Pharmaceutical Care at Ministry of Health in Saudi Arabia 2012 - 2022. J Pharm Pharm Scien. 2015;1(13):1-8.

9. Ahmed AY, Pharm B, Clin PM. A new Guidelines on Hospital Pharmacy Manpower in Saudi Arabia. J Pharm Pract Community Med . 2016;2(22):30-1.

10. Alomi YA. Primary Care Center Pharmacy Manpower New Guidelines in Saudi Arabia. J Pharmacol Clin Res. 2016;1(1).

11. Alomi YA. National Pharmacist Competency System at Ministry of Health Hospitals in Saudi Arabia. J Pharmacol Clin Res. 2016;1(3):1-5.

12. Alomi YA. Patient satisfaction of pharmaceutical care system at Ministry of Health in Saudi Arabia. BAOJ Pharm Sci. 2016;2(1):19.

13. Ahmed Y, Pharm A, Pharm C. National Pharmacy Practice Programs at Ministry of Health in Saudi Arabia. 2015;1(2):17-8.

14. Alomi Y. National Pharmacy Administration Programs. BAOJ Pharm Sci. 2015;1(2):1-2.

15. Alomi YA. National Medication Safety Program at Ministry of Health in Saudi Arabia. J Pharmacovigil. 2015;3(5):e145.

16. McDonough R. Writing a Business Plan for a New Pharmacy Service. The Dynamics of Pharmaceutical Care: Enriching Patients' Health. 2010;23.

17. Harris IM, Baker E, Berry TM, Halloran MA, Lindauer K, Ragucci KR, et al. Developing a Business-Practice Model for Pharmacy Services in Ambulatory Settings. Pharmacotherapy. 2008;28(2):7e-34e.

18. Sachdev G. Sustainable business models: Systematic approach toward successful ambulatory care pharmacy practice. Am J Heal Pharm. 2014;71(16):1366-74.

19. PMBOK Guide. A Guide to the Project Management Body of Knowledge. Sixth Edit. Project Management Institute, Inc. 201 in 


\section{The algorithm (1) of addition or deletion medication at MOH Formulary}

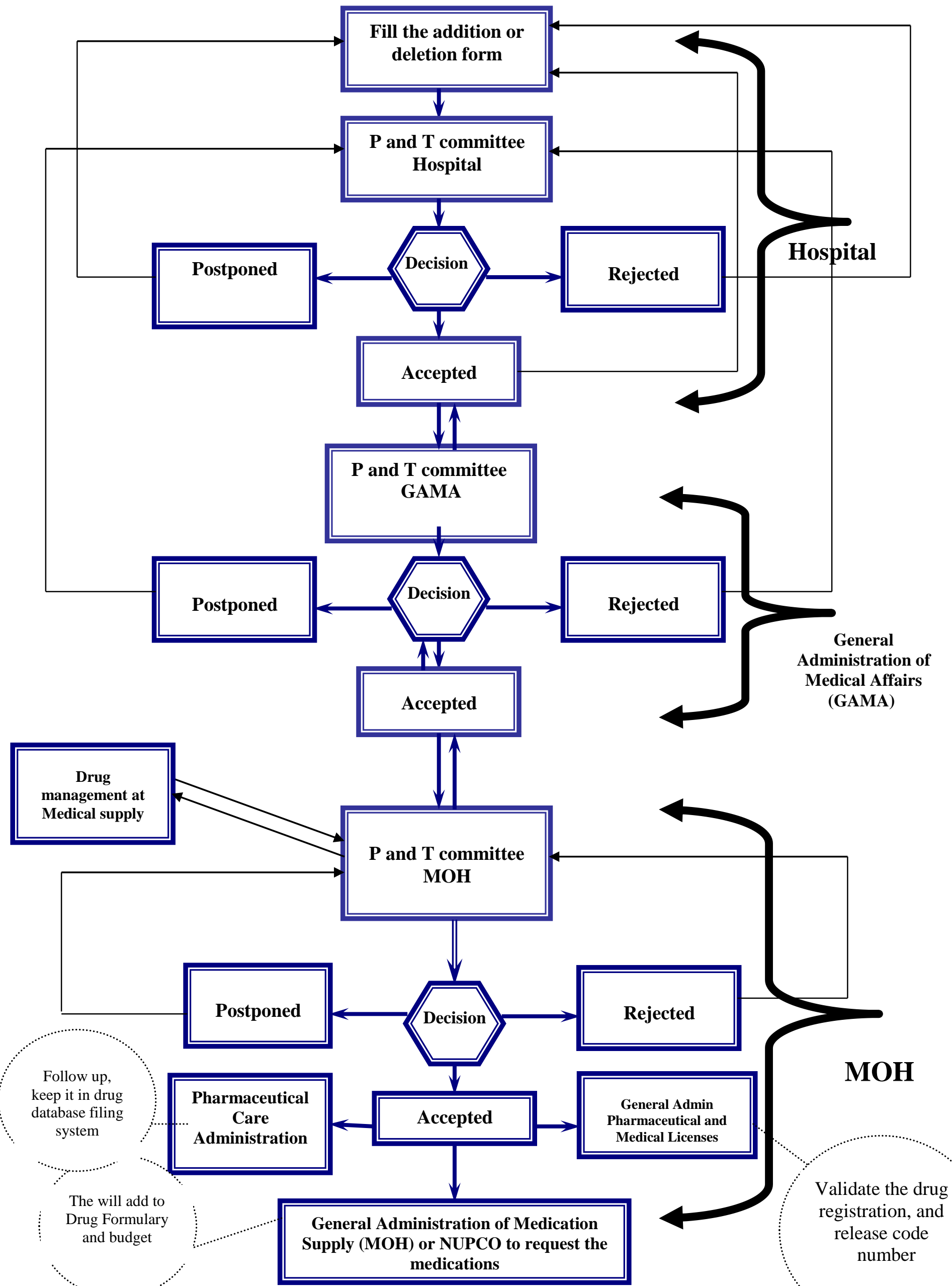

